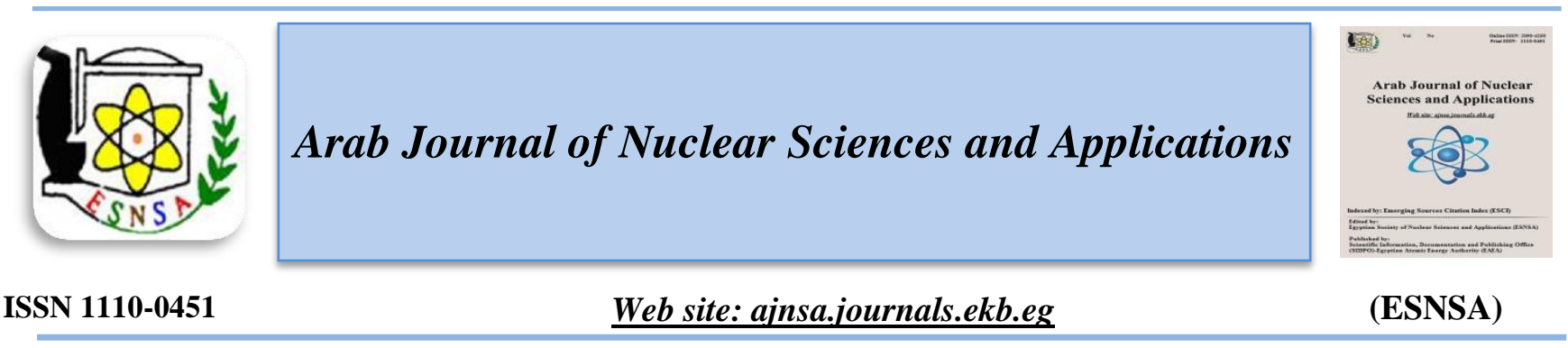

\title{
TE-NORM Radiological Impact and Radiation Protection in Oil and Gas Industry: A review
}

\author{
Omar S. Desouky \\ Radiation Physics Dept., National Center for radiation research and technology, Egyptian Atomic Energy \\ Authority (EAEA), Egypt
}

Received $5^{\text {th }}$ July 2020 Materials having radioactive nuclei and exist naturally on earth are called Naturally Occurring Accepted 13 Jan. 2021 Radioactive Materials (NORM) ${ }^{235} \mathrm{U},{ }^{238} \mathrm{U}$ and ${ }^{232} \mathrm{Th}$ series in addition to ${ }^{40} \mathrm{~K}$ are few examples of radioactive elements and their daughter nuclei. NORM can be found either in soil, in water, in plants, in animals or in human being. It is reported that, in oil and gas industry, NORM accumulates at different locations. Among these locations are the wellheads, pumps and separation vessels. The accumulations may take the form of scales, sludge, scrapings and some other wastes. Unless adequate control procedures are employed, such accumulations may be hazardous to workers, ordinary people and environment. The most critical concern to public health from exposure to NORM is the possibility of development of cancer. Having no threshold dose, the induction of cancer due to radiation exposure is thus a stochastic process. Nevertheless, no acute or severe effects comparable to those due to high doses of radiation are expected in case of exposure to Technologically Enhanced NORM (TE-Norm).In oil industry, deterministic effects due to NORM do not exist even in the worst possible situations. Uncontrolled release of NORM waste will probably contaminate the environment and threaten human health. Such risks can be avoided through the use of a program for NORM control by oil and gas firms. The program will monitor NORM, control contaminated waste, contaminated equipment, train workers and increase their awareness. By the implementation of appropriate protective procedures at work places, one can ensure that the basic principles of radiation protection are functionalized. Therefore, the control of exposure and application of sample dosimetry are the main components of any program for health and safety.

Keywords: Radiation Protection, TE-NORM

\section{Introduction}

Naturally Occurring Radioactive Materials (NORM) are a part of our world. Our planet and its atmosphere contain many different naturally occurring radioactive species, actually almost everything contains NORM. During their daily lives, human beings, as well as, all living organisms are subject to exposure from low level natural nuclear radiation.

Natural radiation is produced due to the radioactive decay of natural radioactive atoms (terrestrial radiation) and is also produced due to nuclear collisions of cosmic radiation from galaxies andthe sun with the atoms of gases in the earth's atmosphere resultingin the so-called secondary cosmic radiation.

Radionuclides belonging to uranium and thorium natural radioactive series existall over the earth, where their concentrations depend on soil composition. Moreover, potassium-40 do exist as well. All of these radionuclides contribute to the radiation dose to human beings. Industrial activities may result in the accumulation of NORM due to a variety of operations. Therefore, the concentration of radionuclides may rise to an extent that radiation protection becomes essential.

Corresponding author: biophysics65@gmail.com

DOI: 10.21608/ajnsa.2021.34760.1378

CScientific Information, Documentation and Publishing Office (SIDPO)-EAEA 
This article aims to discuss the contamination of oil and gas production equipment with NORM, the way workers are exposed to radiation as well as the health effects of the NORM. The article also aims to discuss the radiation protection programs within the oil and gas companies and the methods used to protect workers during routine jobs and during maintenance.

\section{Terrestrial radiation}

The radiation from naturally occurring radioactive elements such as uranium, radium and thorium (in addition to radiation from radioactive nuclei of atoms in naturally occurring materials that surround us) is called "terrestrial radiation". Naturally occurring potassium is marginally radioactive. Our body tissues contain small concentrations of such radionuclides. Materials such as soil, bricks, rocks and tiles may all contain natural radioactivity. One reason to the relatively high concentration of radon gas in poorly ventilated clay brick homes is the decay of radium present in building materials and subsoil to the radioactive radon gas. The latter can diffuse indoors.

One can conclude that we are subject to radiation exposure from terrestrial radiation both internally and externally. Radioactive nuclei may be partially incorporated into our body tissues and bones due to the natural radioactivity in air, food and water we consume. Externally, one may be exposed to gamma radiation from soil, rocks and building material.

\section{Annual radiation exposure to public}

In a normal living environment, the annual radiation exposure to public due to natural background radiation is around 2.4 milli sievert $(\mathrm{mSv})$. Moreover, additional $0.6 \mathrm{mSv}$ annual exposure to the public comes from artificial sources such as exposure during medical imaging procedures [1].

\section{Origin of Naturally Occurring Radioactive Material (NORM)}

In the process of oil and gas recovery, NORM (which is present in different concentrations in the earth's crust) may be further concentrated and enhanced leading to the so-called TechnologicallyEnhanced Naturally Occurring Radioactive Materials (TE-NORM). This takes place either through certain industrial activities leading to an increase in the concentration of NORM or due to the redistribution of the material in response to human interference. TE-NORM may evolve as a by-product in oil and gas production in addition to geothermal production of energy. Among the materials that may contain elevated levels of NORM are sludge, pipe scales and drilling mud. When equipment and materials are reused, the radioactive materials may be trans-located from one site to another [2].

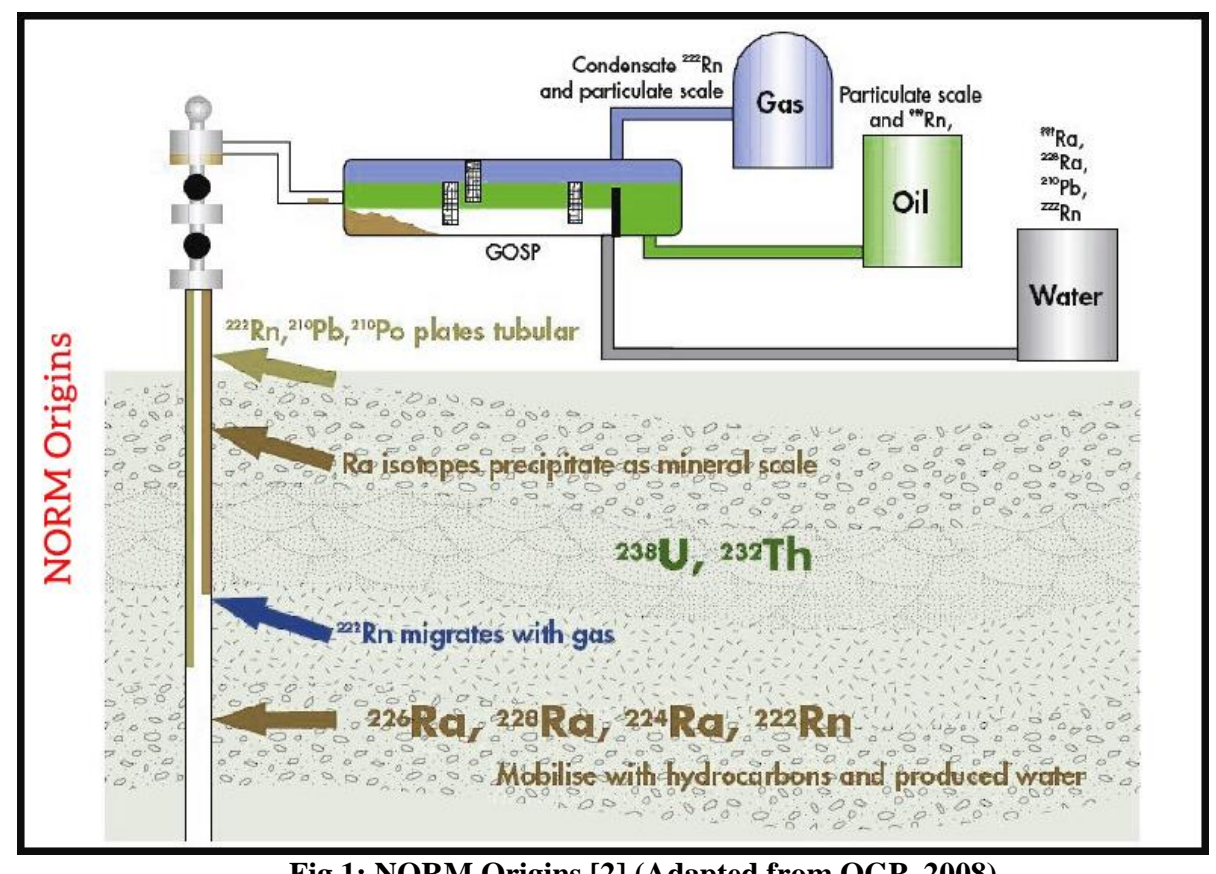

Fig.1: NORM Origins [2] (Adapted from OGP, 2008) 


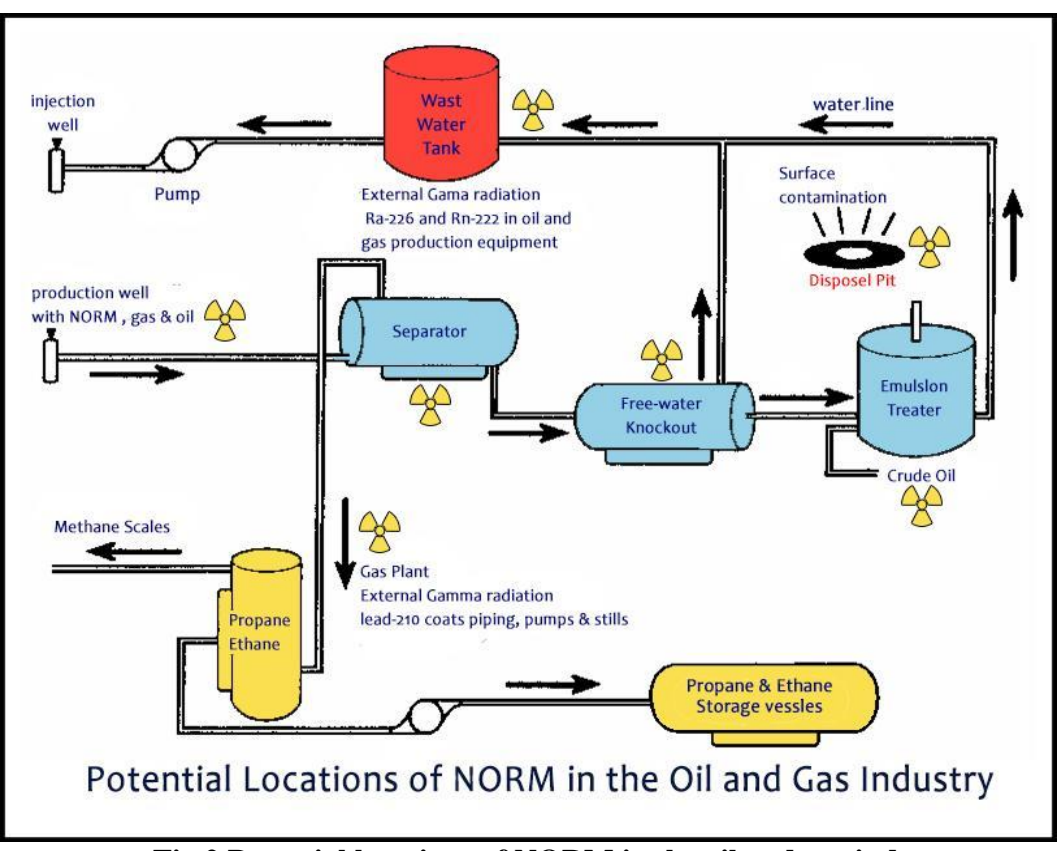

Fig.2 Potential locations of NORM in the oil and gas industry

Radium-226 and radium-228 and their progeny (coming from the decay chains of uranium-238 and thorium-232, respectively) are the main components of NORM that accumulates in surface petroleum production equipment during oil and gas extraction and processing operations. Uranium and thorium are naturally present in underground creations and remain usually in place (Fig.1).

The main contaminant in the waste production streams is radium which can be present in high concentrations in produced water, sludge and scales. Since it is somewhat soluble, radium can dissolve within the liquid phases of a formation to reach the surface with the produced stream of water. It either remains in such solution or precipitates in scales or sludge. When the production and processing equipment are taken off-line for repair, maintenance or replacement (fig. 2), special care should be given to the hazard of exposure to radioactive radium in contaminated water, scales, or sludge $[3,4]$. The quantity of TENORM generated in oil producing fields, and is integrated in the extraction of gas and oil, is directly proportional to the water is produced while oil is being pumped $[5,6]$.

The American Petroleum Institute [7] reported that the produced Oil and gas waste and the ratio of generated water to oil isabout 10:1.

The water that is brought to surface (produced water) includes different cations in solution. These include strontium, calcium and barium. There are also carbonate and sulfate anions, where radium forms radium carbonate and radium sulfate and coprecipitate, while barium and calcium form $\mathrm{BaSO} 4$ and carbonate scales $(\mathrm{CaCO} 3)$ respectively. The co-precipitated scales in oil and gas equipment contain 226Ra and $228 \mathrm{Ra}$ with high specific activities reaching $1.50 \times 107 \mathrm{~Bq} / \mathrm{kg}$ and 0.28 $\mathrm{x} 107 \mathrm{~Bq} / \mathrm{kg}$, respectively. A wide range of different concentrations are also reported [8]. It is noted that sulfate scales are the main type of scales in gas and oil facilities.

Sludge is formed of liquefied solids that precipitate from water in response to the changes in temperature and pressure. These solids are a mixture of mud, sediments, hydrocarbons, natural radionuclides, corrosion particles, bacterial growth and some scale debris [9].

According to the IAEA-TECDOC-1712, the most important radionuclides in sludge are Radium-226, Radium-228, Polonium-210 and lead-210. Radium-226 and Radium-228 are detected in scales, sludge, sand and water. The latter two radioisotopes have lower activity concentrations in sludge compared to scales, with values reaching $0.3 \times 107 \mathrm{~Bq} / \mathrm{kg}$ and $0.2 \times 107$ $\mathrm{Bq} / \mathrm{kg}$, respectively [8]. A thin film of lead-201 (from the decay of radon-222) may contaminate the inner surfaces of natural gas production and processing equipment.

Radon gas which originates in the underground formations is more mobile and dissolves in the organic fraction of petroleum in gas plants. Due to its solubility, it is divided into ethane and propane 
fractions once in surface equipment. The deposits of gas-plants are different from the scales and sludge in oil production as they have a small mass in the form of a thin layer of daughters of radon deported on the inside surfaces of pipes, valves and other equipment in the gas-plants. Fortunately, the half-life of radon is short (3.8 days) resulting in a fast decay to lead-201 (half-life $=22$ years) which is therefore the only remaining radionuclide in gasplant equipment. It decays via beta emission accompanied by low-intensity and low energy gamma rays. Therefore, in most cases, the hazard of its disposal is considerably low when compared to other NORM deposits.

\section{NORM health risks}

Several amounts of natural radioactivity are incorporated in almost all underground natural resources such as natural gas, coal, oil, and mineral ores. After extraction and processing, their natural state is subject to modification leading to an enhancement in the natural content of radioactivity that can be observed in the resulting waste, in residues, in products or by products. Such radioactivity may be too high that, if not properly controlled, will form a health risk to workers, public and environment. NORM may be accumulated in wellheads, pumps, separation vessels in addition to other processing equipment.

The biological effect of radiation to human beings are either stochastic (random) or non-stochastic (deterministic). The latter includes many somatic effects such as cataracts and decrease in white blood cell count. The biological effects depend on the absorbed dose, dose rate and the exposed area of the body. At doses above 0.5 to $1.0 \mathrm{~Sv}$, deterministic effects take place (fig. 3). The given threshold changes with dose rate and the quality of radiation. The effects become more severe with the increase in dose and dose rate.

Non-stochastic effects accompany some incidents in nuclear industries and the use of sources of high activities such as X-ray generators and accelerators $[10,11]$. On the other hand, the development of cancers and genetic mutations are examples of stochastic effects. While the probability of stochastic effects increases with the increase in dose, the intensity of such effects is independent on the absorbed dose [12]. Stochastic effects are non-threshold effects as there is no specific dose or dose rate below which there is zero risk for radiation effects to occur. The most important stochastic somatic effect is the induction of cancer. Therefore, the probability of occurrence of cancer (not its severity) increases with dose.

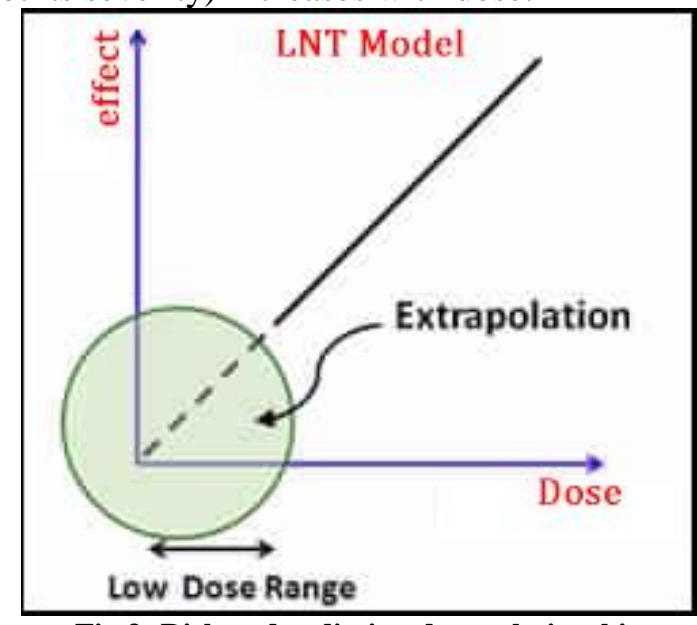

Fig.3: Risk and radiation dose relationship

For high doses of most types of radiation, the relationship between radiation dose and cancer development is well established. On the other hand, at low radiation doses, the effect is not well defined with a high degree of uncertainty as there is no direct cause-effect relationship. This may be attributed to the insufficiency of available data and the possible contribution of environmental stresses to the observed effect.

In such circumstances, one can estimate the risk due to low level exposure to ionizing radiation by the extrapolation of the available high dose data. For such purpose, radiation doses should be converted to corresponding carcinogenic risk factors in ICRP publications $60 \& 103$ [10, 11]. For the public and workers the risk factors are estimated to be $5 \times 10-7$ and $4 \times 10-7$ permrem, respectively. Risks are introduced as the increased probability of lethal cancer over a lifespan [13].

Table 1. Detriment-adjusted nominal risk coefficients for stochastic effects after exposure to radiation at low dose rate $\left(10^{-2} \mathrm{~Sv}^{-1}\right)$.

\begin{tabular}{|c|c|c|c|c|c|c|}
\hline \multirow{2}{*}{$\begin{array}{l}\text { Exposed } \\
\text { population }\end{array}$} & \multicolumn{2}{|c|}{ Cancer } & \multicolumn{2}{|c|}{ Heritable effects } & \multicolumn{2}{|c|}{ Total detriment } \\
\hline & 2007 & 1990 & 2007 & 1990 & 2007 & 1990 \\
\hline Whole & 5.5 & 6.0 & 0.2 & 1.3 & 5.7 & 7.3 \\
\hline Adult & 4.1 & 4.8 & 0.1 & 0.8 & 4.2 & 5.6 \\
\hline
\end{tabular}

A dose of radiation is said to be acute if the energy delivered to tissue is absorbed in few hours or days. On the other hand, if the energy is absorbed in months, years or all over the life span, the radiation dose is said to be chronic. 
Skin burns, hair loss, illness, cancer and birth defects are all possible effects of acute radiation exposure. It is not reported that exposure to TENORM would cause any of these effects or any of the severe effects that may accompany high doses of radiation. This holds true even in the worst possible scenarios, therefore, non-stochastic effects don't take place. On the contrary, delayed effects are possible, these may include the development of cancers such as Leukemia and lung cancer [14].

Special attention should be given to radium, as it is a bone seeker radionuclide that replaces calcium in bones. If radium enters the body in considerably large amounts, it may damage the bone marrow. As a result, the exposed person may show blood disorders, bone necrosis, bone tumors, rupture of cells in tissues and general health breakdown.

\section{NORM Exposure Scenarios}

If a proper radiation protection measure is not taken, the gamma-emitting accumulations of NORM in gas and oil industry may cause considerable exposure to workers and other personnel. The main exposure situations are during maintenance, waste and contaminated equipment transport, equipment decontamination and during waste disposal. At the time of decommissioning of oil and gas production and waste management equipment, similar exposure may also take place [15].

\section{External exposure}

Gamma rays from short-lived daughters of ${ }^{226} \mathrm{Ra}$ and ${ }^{228} \mathrm{Ra}$ present in scale, sludge and sand are the main source of occupational external exposure in the petroleum industry. The amount and activity concentrations of radionuclides lining the inside of pipe lines and vessel walls in addition to the provided shielding determines the dose rate. The maximum dose rate varies from few to several hundred $\mu \mathrm{Sv} / \mathrm{h}[16,17]$. This is almost thousand times the normal background. The only way to minimize such exposure is by maximizing the distance from source and minimizing the exposure time. Access restriction and the control of occupancy time are effective means to potentially minimize the annual exposure dose.

\section{Internal contamination}

The radioactive materials of maximum importance in internal dosimetry are ${ }^{228} \mathrm{Ra},{ }^{226} \mathrm{Ra},{ }^{222} \mathrm{Rn}$ and ${ }^{210} \mathrm{~Pb}$. They are present in the radioactive sludge, scales and sand in substantial activities. Internal exposure to NORM occurs via inhalation of decay products from ${ }^{228} \mathrm{Ra}$ and ${ }^{226} \mathrm{Ra}$ or ingestion and inhalation of airborne radioactive dust. This may take place while working in an open plant and equipment, managing waste materials and surface contamination, and during decontamination of equipment. In order to avoid the ingestion route, precautions must be taken before eating, drinking, or smoking.

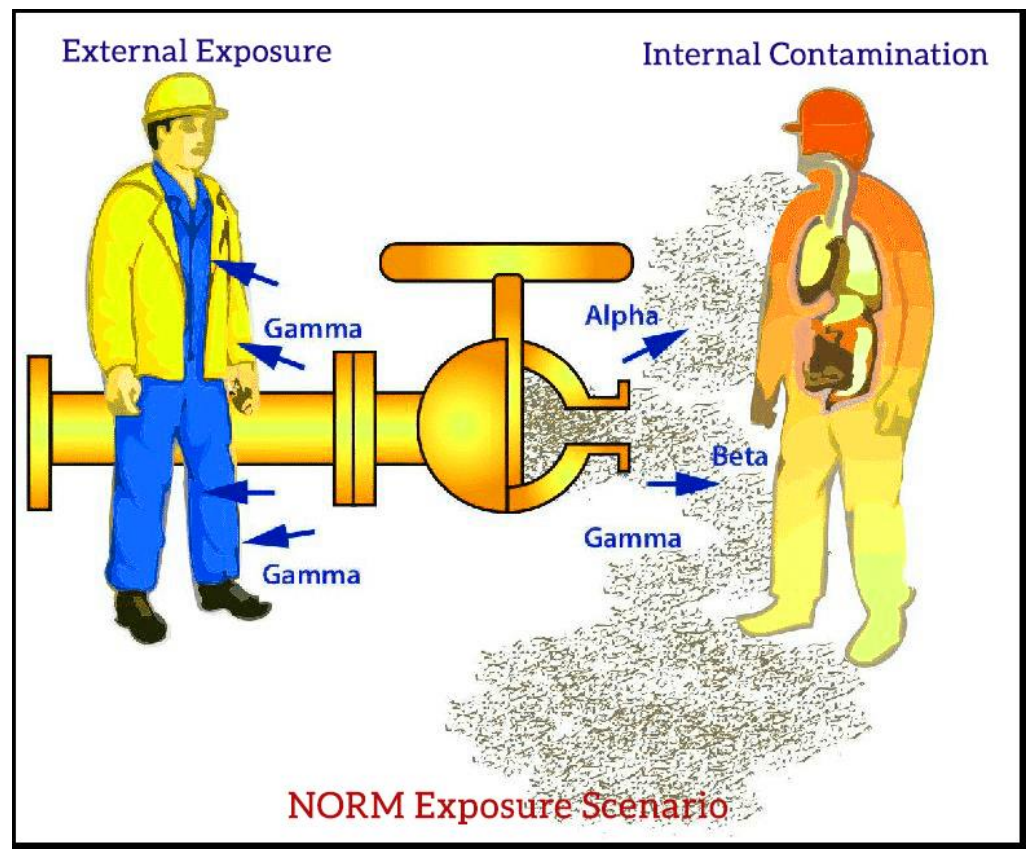

Fig.4: NORM Exposure Scenario [2] (Adapted from OGP, 2008) 


\section{Radiation protection against NORM Risks}

Unrestrained work activities including NORM may result in unnecessary radiation exposure that forms a risk to the health of workers and environment. This risk can be minimized by the employment of suitable controls to detect whether NORM is present and where. The basic principles of radiation protection against possible hazards of ionizing radiation are applied by following the best working practices at working areas containing NORM. Therefore, for the protection of workers, exposure control and proper dosimetry are the most important aspects for any health and safety program. The protection of the public and environment can be achieved by organized disposal of NORM-waste and the implementation of emission controls [18].

The ICRP (2007) reported that there may be a possibility of harmful health effect on exposure to ionizing radiation and supported three main principles for dealing with radiation exposures:

-JUSTIFICATION-No activity including ionizing radiation could be justified unless it is possible to show that it would result in a net positive net benefit.

-OPTIMIZATION - All exposures should be always As Low As Reasonably Achievable (ALARA), where economic and social parameters should be taken into account.

-LIMITATION — The maximum allowable work exposure of any person must not include a radiation risk to that person greater than the risk in case of working in a commonly agreed on as a "safe" industry.

The ICRP (2007) reported that everyone may be liable to a significant exposure from background radiation. Yet, even doses that were less than background and resulting from work activities were unjustifiable if there was no associated benefit, or if they could be easily avoided. Radiation protection and safety requirements introduced in the International Basic Safety Standards (BSS) by the International Atomic Energy Authority (IAEA) are applicable to the NORM in oil and gas industry.

Two common goals to achieve, in all cases are, to maintain radiation doses as low as reasonably achievable (ALARA) below regulatory dose limits for workers and to take economic and social factors into consideration. For the two types of radiation exposure (internal and external), the practical measures to achieve these goals will be principally different.

Most of the regulatory prerequisites for the approval of ionizing radiation in industrial, health, agricultural and basic research activities are based on the linear non-threshold (LNT) radiation protection model.

Based on LNT, any dose presents a risk to genetic (hereditary) material and may cause genetic defects or even cancer no matter how low it is. The risk of development of cancer risk is supposed to increase linearly with radiation dose, with no threshold. LNT was derived by the help of the statistically significant relationship between dose response (DR) due to a radiation dose received by an individual and the observed health effects. The latter were essentially cancer and hereditary disorders [19].

ICRP (2007) reported possible challenges to the LNT model but pointed out that for radiological protection, it was scientifically reasonable to accept that the incidence of cancer or hereditary disorders would increase with increase in the equivalent dose in the related organs and tissues, below about $100 \mathrm{mSv}$ [20].

The National Academy of Sciences Biologic Effects of Ionizing Radiation (BEIR) VII report (1) pointed out that current biological and biophysical low dose data were in favor of a linear-nothreshold (LNT)risk model. This model adopted that even the smallest radiation dose could cause a subtle increase in health risk to humans. UNSCEAR and ICRP reports both endorsed that the LNT model was a practical basis for radiation protection at low doses and low dose rates. They pointed out that the model might not reflect biological differences and risks in the region of low doses [21].

Since clinical indications are not verified for doses below $100 \mathrm{mSv}$, there is no global medical following program for expected low leveldoses due to NORM work processes. Once NORM management procedures are enforced, workers in oil and gas industry may not receive doses higher than the public dose limit of $1 \mathrm{mSv} /$ year. A previously prepared action plan is set for NORM management in order to achieve an appropriate control where the dose can be maintained as low as reasonably practical (ALARP) and the reason for exceeding the dose limit may be considered [18] 


\section{Measures against external exposure}

Routine operations in oil and gas industrial facilities have only a small number of vessel entries per year and therefore workers may be exposed to external radiation than inhaled radioactivity. In order to control low level external exposures, periodic training and awareness about radiation protection against NORM risks should be given to all workers. All pipes and vessels, that may contain NORM, should be marked and all workers should be instructed to follow a routine procedure where the occupancy time and the distance from marked equipment are as low as reasonably practical. In such way it becomes possible to keep the annual effective dose less than $1 \mathrm{mSv}$.

The existence of NORM in oil and gas industrial facilities is unlikely to result in external exposures reaching or exceeding annual dose limits for workers. Therefore, usually, protective measures are not needed.

\section{Measures against internal exposure}

During entries of vessels that are contaminated by scale and sludge, respiratory protective equipment are used by all workers. These are tailored to protect against the inhalation of any possible airborne radioactive particulates. In order to reduce the risk of transferring contamination, disposable coveralls, rubber gloves and rubber boots should be used correctly. Vessel ventilation is very important in storage tanks that are contaminated by sludge so that to evade the inhalation of ${ }^{222} \mathrm{Rn}$. Moreover, employing proper housekeeping practices would help to act against the spread of NORM contamination.

\section{Radiological Exposure for TE-NORM}

Programs designed for monitoring NORM must be enforced by national regulatory bodies in order that a NORM control program could be in effect soon after NORM is detected. This would help to control the risk in an adequate and proportional waythat complies with corresponding national and international legislations. These monitoring programs must be revised periodically because NORM shows faster build up at the end of the life of oil reservoirs.

\section{Protection during routine operations}

Routine operations are day-to-day operations other than vessel entries, dismantling of facility parts, dealing with radioactive waste, etc. Since no worker would face direct contact with NORM in the course of routine operations, it is only important to control external radiation exposures. The most important procedures to control routine radiation exposures are:

- Training workers in the field of radiation protection.

- Performing external surveys of radiation for areas in the facility where NORM has been detected "NORM map".

- Evaluating the average annual radiation dose for the group of workers who are most exposed.

- Identifying the components of the facility that are contaminated with NORM.

It has been reported that if the abovementioned control measures of radiation protection are applied, the annual radiation exposures could be kept less than the public limit of $1 \mathrm{mSv} / \mathrm{year}$ (1,000 $\mu \mathrm{Sv} /$ year) [22].

\section{Protection during shutdown and maintenance}

The activities that are not categorized under the term routine operations and performed by workers in a facility have the potential to deliver high personal radiation exposures and therefore need exceptional control. The most important procedures of NORM control in such condition include:

- Increasing the awareness of staff personnel and contractors about radiation safety.

- Performing surveys of radiation in the workplace before the job starts.

- Carrying job planning that considers relevant work procedures/instructions.

- Performing regular personal monitoring depending on the given task, personal protective equipment, radiation field, etc.

- Ventilating vessels in order to reduce the build-up of radon gas.

- Keeping NORMs wet during the task in order to decrease production of dust.

- Offering personal protective equipment (e.g. rubber gloves and boots, disposable overalls, face masks, etc.).

The petroleum industry has in place progressive safety control system to deal with a wide range of different occupational hazards. NORM work processes and instructions to control the radiation exposures to personnel emerges from similar philosophies as those used in work measures designed to control other hazards in industry. It is also necessary that the staff of petroleum production facilities are trained to perform 
essential radiation protection monitoring and evaluation. This leads to a better staff understanding of radiation protection issues and a higher effective NORM control.

\section{Recommendations}

To avoid the risk of chronic exposure due to low radiation doses from NORM, the oil and gas companies should implement a proper radiation protection and waste management programs which include:

- Training of workers and increasing their awareness.
- Monitoring the annual effective dose to workers with the help of personnel dosimeters

- Detecting contaminated equipment by surveying the different oil and gas facilities using calibrated survey meters.

- During maintenance, workers must use different personnel protective equipment.

- Controlling contaminated equipment by storing in the NORM yard and/or decontaminating the equipment in case of re-use.

- Controlling contaminated waste by disposing in suitable disposalbased on the activity of the waste.

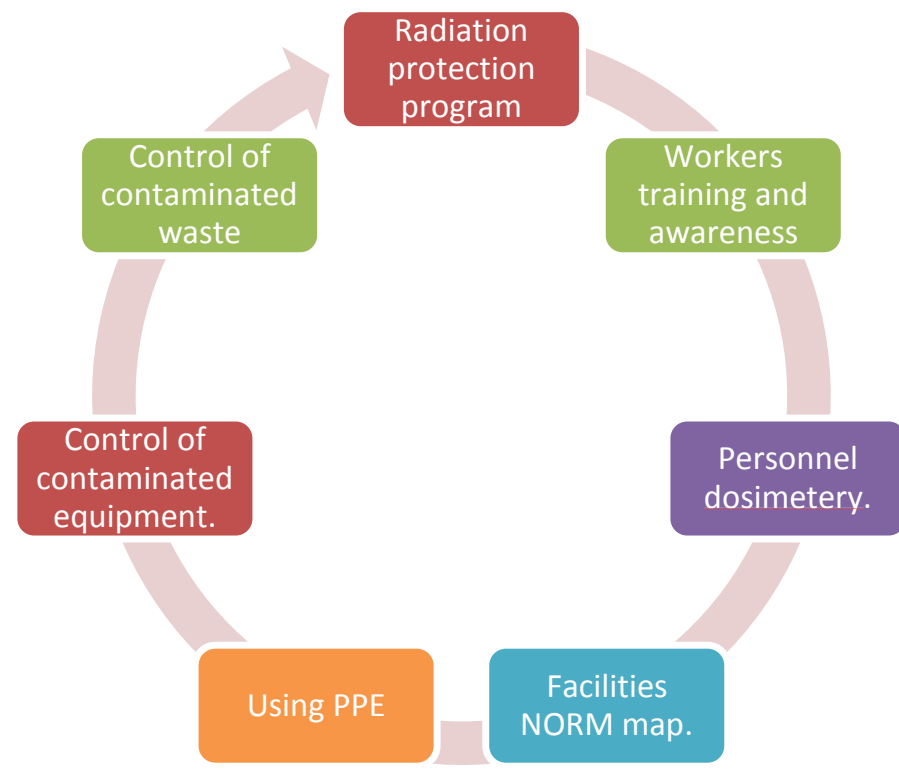

Fig. 4: NORM radiation protection program and waste management in oil and gas companies

\section{Conclusion}

In this review article, the NORM origins in the oil and gas industry was revised, as well as exposure scenarios of workers to radiation and chronic health effects due to exposure to low doses of ionizing radiation. Based on the published results and on the personal experience of the author in following the workers of the oil companies, they do not exceed the limit of the public annual effective dose $(1 \mathrm{mSv} / \mathrm{y})$ during the routine work. Whereas the annual effective dose of the service companies workers who involved in equipment maintenance and decontamination may exceed to $1.8 \mathrm{mSv} / \mathrm{y}$ [35].

It can be concluded that TE-NORM wastes from the oil and gas industry produce levels of radiation exposure that needs special attention and continuous monitoring of NORM during routine activities in this industry. This exposure is mostly due to external and internal radiation from the radioisotopes ${ }^{226} \mathrm{Ra} \&{ }^{228} \mathrm{Ra}$ and their progenies. Finally, the oil and gas companies should apply both; radiation protection program and NORM waste management program on the basis of the national and international regulations to achieve and ensure the safe handling of NORM waste.

\section{References}

1. UNSCEAR (United Nations Scientific Committee on the effects of Atomic Radiation)(2000) Sources and Effects of Ionizing Radiation. Report to General Assembly. Exposures from natural radiation sources. Annex B, United 
Nations, New York.

2. IAOGP(The International Association of Oil \& Gas Producers)(2008) September. Guidelines forthe Management of Naturally Occurring Radioactive Material (NORM) In the Oil \&Gas Industry. Report No. 412.

3. Smith K.P., Blunt D.L., Williams G.P. and Tebes C.L. (1996) Radiological dose assessment related to management ofnaturally occurring radioactive materials generated by the petroleum industry. Report ANL/EAD-2m.ArgonneNational Laboratory, USA.

4. API (1990) Guide for Pressure-Relieving and Depressuring Systems - American Petroleum Institute Recommended Practice 521.Washington, D.C.: American Petroleum Institute, Edition 3.

5. Rood, A. S., White, G. J. and Kendrick, D. T. (1998). "Measurement of Radon-222 Emanation, and Radium-226/Radium-228 Concentration from Injection Well Pipe Scale". Health Physics, Vol. 75, No. 2, pp. $187-192$.

6. Gazineu, M.H.P., Araujo, A.A., Brandao, Y.B., Hazin, C.A., Godoy,J.M. D.O. (2005) Radioactivity concentration in liquid and solidphases of scale and sludge generated in the petroleumindustry. J. Environ. Radioact. 81, 47-54.

7. AP1 (1989) A National Survey on Naturally Occurring Radioactive Materials (NORM) in Petroleum Producing and Gas Processing Facilities. API, Dallas, Texas.

8. Xhixha, G., Bezzon, G.P., Broggini, C., Buso, G.P., Caciolli, A., Callegari, I., De Bianchi, S., Fiorentini, G., Guastaldi, E.,Xhixha, M.K. and Mantovani, F.(2013)The worldwide NORM production and a fully automated gammaray spectrometer for their characterizationJ. Radioanal. Nucl. Chem, 295(1), 445-457.

9. Omar, M., Ali, H.M., Abu, M.P., Kontol, K.M., Ahmad, Z., Ahmad, S.H.S.S., Sulaiman, I. andHamzah, R.(2004) Distribution of radiumin oil and gas industry wastes from Malaysia. Appl. Radiat.Isotopes, 60, 779-782.

10. ICRP (1990) Publication 60. Ann. ICRP $21(1-3)$.
11. Recommendations of the International Commission on Radiological Protection.ICRP (2007) Publication 103.Ann. ICRP 37(2-4).

12. Limacher M.C., Pamela S. Douglas, Guido Germano, Warren K. Laskey,Bruce D. Lindsay, Marlene H. McKetty, Mary E. Moore, Park J.K.,Florence M. Prigent and WalshM.N. (1998) Radiation safety in the practiceof cardiology. March 15, 1998.

13. Smith K.P., Blunt D.L. andArnish J.J. (1998) Potential radiologicaldoses associated with the disposal of petroleumindustry NORM via landspreading. Report DOE/BC/W-31109-Eng-38-5 (DE 98000550). Argonne NationalLaboratory, USA

14. Doyi, David Kofi Essumang, Samuel Dampareand Eric Tetteh Glover (2015) Reviews of Environmental Contamination and Toxicology,Voume 238, pp 107-119.

15. IAEA (2010) Radiation Protection and the Management of Radioactive Waste in the Oil and Gas Industry Training Course Series No. 40.

16. Jonkers, G., Hartog, F.A., Knaepen, A.A.I., $\quad$ Lancee, P.F.J.(1997)Characterization of NORM in the oil and gas production (E\&P) industry, Radiological Problems with Natural Radioactivity in the Non-Nuclear Industry (Proc. Int. Symp. Amsterdam, 1997), KEMA, Arnhem.

17. VAN WEERS, A.W., et al.(1997)Current Practice of Dealing with Natural Radioactivity from Oil and Gas Production in EU Member States, Rep. EU17621, Office for Official Publications of the European Communities, Luxembourg.

18. IAOGP, 2016, Guidelines forthe Management of Naturally Occurring Radioactive Material (NORM) In the Oil \&Gas Industry. Report No. 412.

19. DesoukyO.S., Ding N. and Zhou G. (2015)Targeted and non-targeted effects ofionizingradiation. J. of $\operatorname{Rad} \operatorname{Res}$ and ApplSci, 8, 247 - 254.

20. Wrixon, A. D. (2008). New ICRP recommendations. J. Radiol. Prot., 28, 161-168.

21. Morgan, W. F. and Bair, W. J. (2013). Issues in low dose radiationbiology: the 
controversy continues. A perspective. RadiatRes, 179, 501-510.

22. Kvasnicka, J.(1996) Radiation protection in the offshore petroleum industry. In Proceedings of the international congress on radiation protection, IRPA (Vol. 9).

23. API (American Petroleum Institute)(1991) Produced waterradionuclides hazard/risk assessment, Phase 1. API 1220 LStreet, NW Washington, DC

24. Stephenson, M.T. andSupernaw, I.R.(1990) Offshore OperatorsCommittee 44 Platform Study Radionuclide Analysis Results.Offshore Operators Committee, New Orleans, Louisiana

25. IAEA(2003) Radiation Protection and the Management ofRadioactive Waste in the Oil and Gas Industry. Safety Series,No. 34, ISBN 92-0-114003-7.

26. Steinhausler, F. (2004) Radiological Impact on Man and the Environment from the oil and gas industry: risk assessment for critical group. In: Zaidi MK, Mustafaev I (eds) Radiation safety problems in the Caspian region. NATO Sciences Series, vol. 41. Kluwer Academic Publisher, New York, 129-134.

27. Bou-Rabee, F., Al-Zamel, A.Z., Al-Fares, R., Bem, B. (2009) Technologically Enhanced Naturally Occurring Radioactive Materials in the oil industry (TENORM).A review.Nukleonika, 54, 3-9.

28. Hamlat, M.S., Djeffal, S. andKadi, H.(2001) Assessment of radiationexposures from naturally occurring radioactive materials inthe oil and gas industry.Pergamon, 55, 141-146.

29. Lysebo, I. and Strand, T.(1996) NORM in oil production-occupational doses and environmental aspects.Procedingsof the NRPS 11th Congress, Iceland, August 1996

30. Strand, T., Lysebo, I., Kristensen, D. andBirovljev, A.(1997) Radioaktiveavleiringer i oljeoggassproduksjon.Stralevernrapport19987/ 1, Norvegian Radiation Protection AuthorityReport 197:1, Language:Norveigian.

31. Strand, T., Lysebo, I.(1997) NORM in oil production inNorway. Proceedings of the NORM I, Amsterdam, September8-10.
32. NPRA(1997) Annual Meeting: March 1618, 1997, Convention Center, San Antonio, Texas,

33. National Petroleum Refiners Association

34. Bakr, W.F.(2010) Assessment of the radiological impact of oil refining industry. J. Environ. Radioact, 101(3), 237-243.

35. Wang, S. and Landsberger, S. (2016) MCNP modeling of NORM dosimetry in the oil and gas industry. J. Radioanal. Nucl. Chem, 309(1), 367-371.

36. Desouky O. S. and Morsi T. M. (2018) Evaluation the Annual Effective Dose of the NORM Decontamination Workers During Cleaning the Oil and Gas Equipment. Arab J. Nucl. Sci. \& Applic., 51 (4), 44-50. 